\title{
Philosophie et politique chez Arturo Andrés Roig. Vers une philosophie de la libération latino-américaine (1945-1975).
}

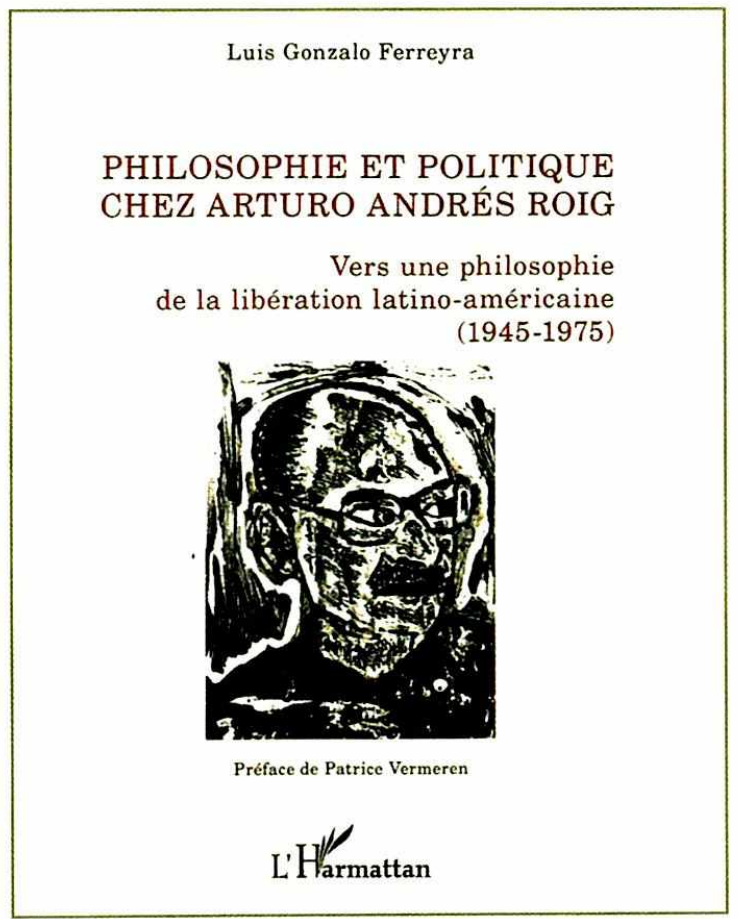

Este libro publicado en Francia sobre el pensamiento filosófico y político del pensador argentino Arturo Roig, se diferencia de los estudios anteriores dedicados al análisis de su obra en la medida en que se hace cargo de las etapas anteriores a la década de los setenta, en que el autor de Teoría y Crítica del pensamiento latinoamericano, aparece como uno de los teóricos más importantes del pensamiento latinoamericano, filósofo de la liberación y de la recuperación crítica de la historia de las ideas. Se trata de un largo periodo que va desde finales de los años treinta hasta los setenta, propiamente cuando Roig emerge como filósofo de la liberación en Argentina. Sin embargo, el problema para este análisis es doble: por una parte, en la obra del pensador argentino que se inicia en los setenta apenas

\author{
Joaquín Hernández Alvarado
}

aparecen huellas teóricas del primer período del que Ferreyra intenta ocuparse. Como dice este, pareciera que el mismo Roig hubiese quemado todos los indicios de su pasado intelectual y político, pasado que ocupó tres décadas más o menos. ¿Se trataría entonces de "dos Roig" o de un "Roig contra Roig", como titula muy adecuadamente Patrice Vermeren al prólogo en que presenta el libro? El segundo problema es teórico y metodológico y pone en cuestión el intento del libro de Ferreyra: las preocupaciones teóricas y lecturas filosóficas del Roig anteriores a la década de los setenta tienen, al parecer, poco que ver con las tareas asumidas a partir de dicha década: la fundamentación crítica del pensamiento latinoamericano y de la historia de las ideas y la formulación de un pensamiento "propio". O de un saber de liberación que pone en crisis no solo al saber académico, sino sobre todo que cuestiona a la institucionalidad de la época. Se encuentran solo determinadas referencias a Platón, los comentarios sobre sus maestros Nimio de Anquín, Miguel Ángel Virasoro o Carlos Astrada, en que se critica al ontologismo y se afirma a los entes sobre el ser, pero a pesar de ello no pasan de ser eso, referencias. ¿Cómo justificar entonces un estudio sobre este período del pensador argentino como el pretendido por Ferreyra? 
Como se sabe, la figura de Roig es conocida internacionalmente como filósofo del pensamiento latinoamericano, historiador de las ideas e incluso, como filósofo de la liberación en la acepción que el pensador mendocino dió a dicha palabra. Los estudios de su obra se han dedicado al análisis y desarrollo de esta compleja temática, ubicada a partir de los años setenta hasta el presente: es el caso de Horacio (Cerutti, Fïlosofando y' con el mazo dendo; Adriana Barrionuevo, lítica j' discurso en Arturo Roig: y; Carlos Pérex Zavala, La filosofia latinoamericana como compromiso, para citar algunos de los más conocidos. Ferreyra considera a estos estudios, pese a su innegable valor teórico e histórico, unidimensionales. Toda la obra de Roig aparecería dominada por esta segunda etapa, para la cual la primera sería solo de iniciación, destinada a desaparecer a partir de los setenta. Dentro de la preocupación por lo "latinoamericanista", Ferreyra ve en Roig un pensador clave que afronta la tensión entre filosofía y política sin hacer de ninguna de ellas el polo privilegiado. Precisamente por ello, su búsqueda de este Roig casi desconocido donde la formación y desempeño como profesor universitario por una parte $y$ de experto en Platón en otra, se muestran en su apertura frente a lo político. En todo caso, este primer período no se reduce a ser simplemente antecedente del segundo ni, según sostiene el autor del libro, queda sepultado por el Roig de los setenta en adelante.

Lo que nos lleva a la pregunta de cómo se formó Roig y qué pensó antes de rolverse, a mediados de los años setenta, como filósofo latinoamericanista, historiador de las ideas y; en sentido amplio, filósofo de la liberación. Ferreyra no se plantea por ello una lectura "postfactum" de Roig, es decir leer desde los textos posteriores a los del año 73 , que son los más conocidos, el Roig de las etapas de formación desde finales de los 30 hasta su aparición como filósofo latinoamericano. El propósito del libro, según Ferreyra, "rompe con el comentario académico de su obra, que toma a veces aires canónicos".

Ferrevra considera por tanto que es necesario analizar este primer periodo, sin imponerle, como camisa de fuerza intelectual, al Roig post factum como le llama, el del segundo periodo. Por ello el libro se ocupa de este primer periodo de Roig en dos etapas: la que titula "Universidad y compromiso político" y la segunda, "Estudios clásicos o la fuerza actual del Platonismo en sus escritos contemporáneos".

En la primera aparece un Roig "reformista" " pedagogo, humanista, que termina en la radicalización política siguiendo a ello el ritmo de la sociedad argentina de estas clécadas. Se trata del inicio de la actividad filosófica del pensador argentino en la Lniversidad de Mendoza, preocupado por el problema de la pedagogía en la universidad argentina y de la misión de la misma, sobre todo en los períodos que van de la caída de Perón en 1955 hasta 1975, pasando por las presidencias de Frondizi e llía, las clictaduras militares de Onganía, lanusse y el breve período de la presidencia de Héctor J. Cámpora en 1973. Punto especial de discusión merece aquí la posición política de Roig frente al fenómeno del peronismo que se apoderó de la agenda política de los intelectuales de esas décadas, la radicalización de los mismos y la pérdida de referentes de un pensamiento liberal democrático. $\mathrm{Al}$ final asistimos a lo que Ferrẹra llama su radicalización filosófico-político-pedagógica, impulsada por su conocimiento de la "Teoría de la dependencia" y el contacto con los pedagogos brasileños Paulo Freire ए Darcy Ribeiro. Para Roig fue además sumamente importante el cuestionamiento que se dio al final de este período al antipositivismo de 1930 que encerraba a la actividad filosófica en el marco de la normalización institucional universitaria. 
La segunda etapa, muestra las preocupaciones teóricas de Roig centradas en la filosofía antigua, concretamente en la figura de Platón y el significado de su lectura que casi desaparecería en la construcción teórica del "a priori epistemológico" de mediados de los setenta donde la presencia del Hegel de la Fenomenologia del Espiritu, Lecciones sobre la filosofia de la bistoria miniersal.) Principios de la filosofía del derecho, resulta avasalladora y donde los demás filósofos modernos, Kant, Spinoza y Descartes ocupan un segundo plano. ¿Por qué ese salto de preferencias de un experto en filosofia antigua a la moderna? Ferreyra no lo considera así y piensa que la identificación intelectual de Roig con el platonismo en especial y con la filosofía clásica griega en general, figura en la figura de un "curriculum oculto" que precisamente permite teóricamente el planteamiento de Teoria y' critica del pensamiento latinoamericano de 1981.

Para ello, Ferreyra hace un estudio sobre los tres filósofos franceses con los que más habría estado en contacto Roig durante su estancia en Paris entre 1953 y 1954: PierreMaxime Schuhl y su lectura de Platón; Jean Wahl y su visión de lo concreto y Jean Hyppolite, el conocido analista e historiador de Hegel cuya obra sobre la Fenomenología del Espiritu fue considerada clave. Lo que encontramos en este período es lo que Ferreyra denomina un primero y un segundo platonismo, que muestran los "movimientos de ruptura $y$ de fidelidad del pensamiento roigiano". "L'idéalisme gnoséologique des années 50 se convertirá, grâce a la passion pour la histoire que son culturalisme de jeneusse assurait, en la question épistémologique sur l'origine et l'existence de la philosophie latino-americaine". Hay todo un camino intelectual que Ferreyra analiza desde las primeras lecturas de Platón a la ontología entis, de la filosofía de la conciencia al sujeto histórico, de Platón a los filósofos de la sospecha. Para Ferreyra, Platón y la filosofía clásica no quedan sepultados por el Roig posterior, sino que de las dos interpretaciones de Platón que Roig ha elaborado en su estadía en Francia y en diálogo con los filósofos arriba mencionados, -- los dos platonismos-el pensador mendocino termina escogiendo uno, "el del hombre y" no el del ser", "solo en el momento en que reduce las ideas (onsia) a una estructura de carácter <<eidético-óntico >>, es cuando el a priori puede surgir de la experiencia gracias a la acción del poner del sujeto; se puede hacer del platonismo un inmanentismo y una antropologia". Como concluye Ferreyra al final del capítulo, Roig se separa en 1970 del platonismo esencialista de su juventud, sin por ello decir adiós a Platón o a la experiencia fundadora de sus estudios clásicos.

La justificación de su libro sobre Roig la ha planteado Ferreyra con las palabras del filósofo argentino Hugo Biagini, "Arturo Andrés Roig a joué un role fundamental, dans et hors du pays dans la exploration d'insoupçonnés chemins doctrinaux et dans l'élaboration de nouvelles catégories théoriques et historiographiques". Dicho en términos de Ferreyra el esclarecimiento del lugar nodal de Roig en la circulación de los saberes filosóficos en sus dimensiones históricas y contemporáneas. Pertenece a este primer objetivo la recepción latinoamericana de la filosofía francesa y europea en un autor latinoamericano. Aquí se inscribe el Prefacio del libro escrito por el filósofo francés, $\mathrm{Pa}$ trice Vermeren, "Roig contre Roig?", y que se pregunta por qué leer a Roig hoỵ. Una de las razones para hacerlo, según Vermeren, es la pertenencia de Roig a dos tradiciones: la europea y la latinoamericana. ¿Se da en Roig el reencuentro de estas tradiciones?, así pareciera pensar Vermeren cuando afirma que el filósofo argentino "puede sostener que la historia de la filosofía ha sido reemplazada en el pensamiento latinoamericano por la historia de las ideas, pero no cesa, para lograrlo, de movilizar los conceptos y las figu- 
ras de la historia de la filosofía, de Platón a Kant y de Hegel a Foucault". $\Lambda$ sí también se desprende, al final del libro, cuando se concluye que la identificación de Roig con Platón permanece en la obra posterior y que de hecho, el lugar clave que ocupa el "a priori antropológico" en la obra del pensador argentino, es resultado del movimiento teórico de la preeminencia de la dianoia frente a la noesis, de la natura naturans frente a la natura naturata.

En segundo lugar, el esclarecimiento de la relación intrínseca entre filosofía y política en la obra del pensador argentino. Este tema trae aparejadas otras cuestiones: la identidad del filósofo como tal y la posibilidad de que su toma de posición frente a la coyuntura política frente a la cual se define, lo atrape en su circunstancialidad. ¿Cuál fue el papel del filósofo Roig frente a la historia argentina de su tiempo, es decir frente a la política y su relación con el pensamiento? No se trata de una relación casual. En la lectura del libro de Ferreyra, la política ocupa frente a la filosofía la "prueba" de esta última como lo fue la Ciencia de la Naturaleza para Kant en la Crítica de la razón pura. En el caso de Roig, la "lucha de gigantes sobre la esencia" a la que se refiere el conocido texto del filósofo de Könisberg, se debate en el ruedo de la política es la que produce los vaivenes teóricos de la filosofía, eco no muy lejano por cierto de la conocida frase de Hegel de que aquella "es la época puesta en pensamientos".

El Roig que surge de la lectura de "Philosophie et politique chez Arturo Andrés Roig" es un Roig más problemático -son los años de fundación de su propio pensamiento-nunca divorciado del pensamiento europeo, --por lo menos de esa etapa del pensamiento europeo--, latinoamericanista pero occidental. Aparece también un Roig que rompe con la imagen retrospectiva de su filosofía que él mismo ha difundido, y que por ello tiene que recomenzar siempre, no cerrándose, sino asumiendo que la filosofía es siempre una "segunda navegación" en la figura planteada por Aristóteles en la "Ética a Nicómano". Cercano a un eclecticismo del siglo $\mathrm{XX}$ cuya primera figura apareció en la Argentina del siglo XIX. Ia última pregunta que cerraría esta recensión es analizar por qué esta vocación de recomienzos permaneció polémica y contraria a los recomienzos de la filosofía occidental europea de finales del siglo XX, a la postmodernidad, concretamente. 